\title{
Factors Associated with Hepatitis B Surface Antigen Seroprevalence amongst Pregnant Women in Kenya
}

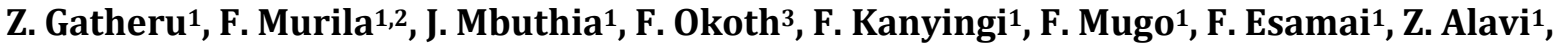 \\ J. Otieno' ${ }^{1}$ H. Kiambati ${ }^{4}$, N. Wanjuki ${ }^{4}$, M. M. Obimbo ${ }^{2 *}$ \\ ${ }^{1}$ Virus Research Center, Kenya Medical Research Institute, Nairobi, Kenya \\ ${ }^{2}$ Department of Human Anatomy, Obstetrics and Gynecology, University of Nairobi, Nairobi, Kenya \\ ${ }^{3}$ Kenya Pediatrics Association, Nairobi, Kenya \\ ${ }^{4}$ Ministry of Health, Nairobi, Kenya \\ Email: *obimbomad@gmail.com
}

How to cite this paper: Gatheru, Z., Murila, F., Mbuthia, J., Okoth, F., Kanyingi, F., Mugo, F., Esamai, F., Alavi, Z., Otieno, J., Kiambati, H., Wanjuki, N. and Obimbo, M.M. (2018) Factors Associated with Hepatitis B Surface Antigen Seroprevalence amongst Pregnant Women in Kenya. Open Journal of Obstetrics and Gynecology, 8, 456-467.

https://doi.org/10.4236/ojog.2018.85052

Received: April 8, 2018

Accepted: May 6, 2018

Published: May 9, 2018

Copyright ( 2018 by authors and Scientific Research Publishing Inc. This work is licensed under the Creative Commons Attribution International License (CC BY 4.0).

http://creativecommons.org/licenses/by/4.0/ (c) (i) Open Access

\begin{abstract}
Background: Knowledge of factors associated with seroprevalence of Hepatitis $B$ in pregnancy is important in informing policies towards prevention of vertical transmission of Hepatitis B Virus (HBV) infection, since in-utero and perinatal infection lead to chronic carrier state with severe long-term sequela. In addition, adequate and timely immunization plays a major role in the prevention of transmission. Objective: To determine the factors associated with $\mathrm{HBs}$ Ag seroprevalence in pregnant women from various geographical regions in Kenya. Methods and Subjects: This was a cross-sectional survey amongst all pregnant women attending antenatal clinics in Kenyatta National Hospital and 8 other hospitals from different regions of Kenya in their third trimester of pregnancy among June 2001 to June 2002. For each pregnant woman, age, history of intravenous drug use, sexually transmitted disease (STD), liver diseases, alcohol intake, blood transfusion (BT) and presence of traditional scarification were documented. HBs Ag serology was assayed at the Kenya Medical Research Institute (KEMRI) laboratory. Results: A total of 2241 pregnant women were enrolled in the study, 2196 consented, of whom 205 (9.3\%) tested positive for HBs Ag. A significant association was found between HBs Ag seroprevalence and traditional scarification $(p=0.029)$, history of blood transfusion $(p=0.0024)$ and alcohol intake $(p=0.05)$. There was no significant association between Hbs Ag seroprevalence and sexually transmitted disease $(p=0.64)$. It was not possible to evaluate the association of $\mathrm{HBs} \mathrm{Ag}$ seroprevalence with history of hospitalization for any liver disease including Hepatitis A, B or C, history of intravenous drug use or contact with sex part-
\end{abstract}


ners previously hospitalised for any liver disease including Hepatitis A, B or C as the numbers with these attributes were small. Conclusions: We found 9.3\% of pregnant women were $\mathrm{HBs} \mathrm{Ag}$ positive, significantly higher than previously observed. The high seropositivity was associated with traditional scarification, history of blood transfusion and alcohol intake. Proper screening of blood transfusion products, immunization and control of scarification and alcohol use should be considered by health policy experts.

\section{Keywords}

Hepatitis B, Seroprevalence, Pregnancy, Immunization, Transmission

\section{Introduction}

Hepatitis B virus (HBV) infection poses a significant global public health challenge [1]. The virus is more infectious than the human Immunodeficiency virus (HIV) and unlike HIV it can live outside the body in dried blood for longer than a week [2]. HBV is transmitted via infected blood or blood products, sexual contact and perinatal transmission from infected mother. The relative importance of the various routes of transmission differs between different regions of the world. HBV is a major cause of morbidity and mortality in developing countries due to the high prevalence of carrier state and low average age of infection [2] [3]. In these regions, $\mathrm{HBV}$ is not restricted to those with known risky behaviors and other factors are responsible for the horizontal spread of the virus [1]. Whereas in North America and Western Europe infection usually occurs in adults via sexual contact or exposure to contaminated blood, in Sub-Saharan Africa the major route of infection is through close contact between children, constituting horizontal transmission [2] [3].

The epidemiology of HBV is complicated by the presence of chronic carriers and multiple routes of transmission. There is a high age-dependent risk of developing the carrier state in Sub-Saharan Africa with approximately $90 \%$ of the infants going on to become carriers following infection whereas only $10 \%$ or less develop the chronic state [1] if infected late.

The mode of transmission of HBV infection has also been found to vary from time to time and from urban to rural areas. There are widespread reports of higher infection rates in rural versus urban areas associated with poverty and lower Social Economic status (SES) [4]. The main determinant of HBV prevalence in many rural areas appears to be horizontal transmission aided by cultural and behavioral factors with possible clustering of carriers [4]. Nevertheless, there are still no clear factors for transmission in $20 \%-30 \%$ of patients [3].

Kenya is comprised of various ethnic groups with different cultures and traditions that are practiced and carry a risk of enhancing HBV transmission [5] [6]. In this study, we aimed at highlighting possible factors responsible for horizontal transmission of HBV infection. 


\section{Materials and Methods}

\subsection{Study Design}

This was a multicenter, hospital based, cross-sectional study conducted in nine sites representing six regions in Kenya. Upon receiving information on the nature of the study, potential risks, benefit and participant obligations, those who consented to the study signed a written informed consent.

\subsection{Study Population}

This included women in third trimester of pregnancy (from 28 weeks gestation to delivery) attending antenatal clinic in the nine study sites from $22^{\text {nd }}$ June 2001 to $10^{\text {th }}$ June 2002 . All eligible women were recruited. Only those who refused to consent to the study were excluded.

\subsection{Study Sites}

Six study sites in nine geographical regions which represented national ethnic diversity were selected. The Kenyatta National Hospital (KNH) represented the Nairobi region. This is the major national referral hospital situated in the Capital with bed capacity of 1800 and has about 1500 deliveries every month. The Aga Khan Hospital and the Coast general hospital represented the Coast region. These are a private facility and a government provincial hospital respectively. The Nyeri provincial hospital which is a level 5 referral hospital represented the central region while the eastern region was represented by Isiolo district hospital, a level 5 county hospital. The vast rift valley region was represented by three sites; the Nakuru level 5 hospital situated in Nakuru town and serves as a referral centre for the central Rift, the Moi teaching and referral hospital situated in Eldoret and serves as a national referral hospital and the AMREF Lopiding static health facility which serves the nomadic community of the north rift. The Western region was represented by the Jaramogi Oginga Odinga referral hospital in Kisumu which serves the Nyanza area (Table 1).

\subsection{Methodology}

Demographic data was obtained from all the subjects. Information on STD, alcohol consumption, Intravenous drug use, history of blood transfusion, history and presence of traditional scarification, sex partner previously hospitalized for any liver disease including Hepatitis A, B, or C, and previous hospitalization for any liver disease including Hepatitis A, B or C was obtained.

The women were then examined and gestation confirmed after which a blood sample of $10 \mathrm{ml}$ was obtained for serological determination of hepatitis B markers.

A total of 300 pregnant women were included per study geographic region except in the Rift Valley area (South, Central and North Sites D, E, and F respectively) where 741 pregnant women were recruited. Forty-five women did not complete the study were excluded due to incomplete data. 
Table 1. Study geographic regions and sites.

\begin{tabular}{|c|c|c|c|c|}
\hline \multirow[t]{2}{*}{$\begin{array}{c}\text { Study Geographic } \\
\text { Region }\end{array}$} & \multirow[t]{2}{*}{$\begin{array}{l}\text { Study Site } \\
\text { Code }\end{array}$} & \multirow[t]{2}{*}{ Study Site/City } & \multicolumn{2}{|c|}{$\begin{array}{l}\text { Number of subjects } \\
\text { Included }\end{array}$} \\
\hline & & & $\mathrm{N}$ & $\%$ \\
\hline Total & & & 2241 & 100 \\
\hline Nairobi & A & $\begin{array}{l}\text { Kenyatta National Hospital Nairobi } \\
\text { (City) }\end{array}$ & 300 & 13.4 \\
\hline \multirow[t]{3}{*}{ Coast } & $B$ and I & & 300 & 13.4 \\
\hline & B & $\begin{array}{c}\text { Aga Khan Hospital, Mombasa } \\
\text { (Municipal town) }\end{array}$ & 100 & 4.5 \\
\hline & I & $\begin{array}{l}\text { Coast General Hospital, Mombasa } \\
\text { (Municipal town) }\end{array}$ & 200 & 8.9 \\
\hline Nyanza/Western & $\mathrm{C}$ & $\begin{array}{l}\text { New Nyanza Provincial General } \\
\text { Hospital, Kisumu (Municipal town) }\end{array}$ & 300 & 13.4 \\
\hline Rift Valley & $\mathrm{D}, \mathrm{E}$ and $\mathrm{F}$ & & 741 & 33.1 \\
\hline $\begin{array}{l}\text { Rift Valley } \\
\text { (Central Rift) }\end{array}$ & $\mathrm{D}$ & $\begin{array}{l}\text { Rift Valley Provincial General Hospital, } \\
\text { Nakuru (Rural town) }\end{array}$ & 233 & 10.4 \\
\hline (West Rift) & $\mathrm{E}$ & $\begin{array}{l}\text { Moi Teaching and Referral Hospital, } \\
\text { Eldoret (North Rift/Western) } \\
\text { (Rural town) }\end{array}$ & 208 & 9.3 \\
\hline (North Rift) & $\mathrm{F}$ & $\begin{array}{l}\text { AMREF Lopiding Static Health Facility } \\
\text { (Rural town) }\end{array}$ & 300 & 13.4 \\
\hline Eastern & G & Isiolo District Hospital (Rural town) & 300 & 13.4 \\
\hline Central & $\mathrm{H}$ & $\begin{array}{l}\text { Nyeri Provincial General Hospital } \\
\text { (Rural town) }\end{array}$ & 300 & 13.4 \\
\hline
\end{tabular}

\section{Management of Blood Samples}

A $10 \mathrm{ml}$ sample of venous blood was collected into a vacutainer tube on first contact. The blood sample specimens were centrifuged at $3000 \mathrm{rpm}$ for $15 \mathrm{mi}-$ nutes then stored in cryotubes at minus $20^{\circ} \mathrm{C}$ until processed in KEMRI where analysis was done using the following Kit:

R-PHA-KEMRI-Hep-Cell kit for HBs Ag (KEMRI in-house Reverse passive Haemagglutination test), (Specificity 99\% and Sensitivity 98\%) [7].

\section{Statistical Analysis}

Categorical variables were summarized using simple proportions and percentages. Continuous variables were summarized using means and confidence intervals. Comparison of the prevalence of Hepatitis B between different factors was done using the Chi-square statistics and Odds Ratios and their $95 \%$ confidence intervals were estimated [8].

\section{Ethical Considerations}

Ethical approval was obtained from the ethical committees of all the hospitals involved and all the women enrolled into the study signed a written informed 
consent form. All infants born to the study subjects were given a total of three hepatitis $\mathrm{B}$ vaccines free of charge starting at birth.

\section{Results}

A total of 2241 pregnant women were included in this study between 22 June 2001 and 10 June 2002 in 9 study sites representing six regions in Kenya. The results of the overall and regional $\mathrm{HBs} \mathrm{Ag}$ prevalence and differences between regions were presented and discussed in the first paper of this study [6]. Data for the associated factors was available for 2196 who consented and completed the study, 45 women did not complete the study. Of these a total of 205 mothers (9.3\% 95\% CI 8.1 - 10.5) were HBs Ag positive.

Only 2 of the study subjects gave a history of intravenous drug use and none of these were HBs Ag positive. Similarly, 3 subjects had sex partners who had been previously hospitalized for liver disease including Hepatitis A, B or C but none were positive for $\mathrm{HBs} \mathrm{Ag}$.

The age of women recruited in the study ranged between 12 and 43 years. The age groups were as follows: 12 - 22, 23 - 27 and 28 - 43, and as the seroprevalence of HBs Ag was similar at $9 \%, 10 \%$ and $9 \%$ respectively (Table 2 ).

Although other demographic and cultural factors may influence HBs Ag seroprevalence, besides scarifications, blood transfusion, alcohol and STD, the latter are known to be the most important modes of HBV transmission.

A higher proportion of women who had traditional scarification (11.9\%) were positive for the HBs Ag compared to those without scarification (8.6\%). This difference was statistically significant $(p=0.029)$.

The HBs Ag seroprevalence of $23.9 \%$ found in women who had undergone blood transfusion was more than twice the seroprevalence of $\mathrm{HBs} \mathrm{Ag}$ of $8.9 \%$ found in those who had had no blood transfusion. This difference was also statistically significant $(p=0.001)$. Women who reported alcohol intake had a higher HBs Ag seroprevalence when compared to those who did not report any alcohol intake ( $15.6 \%$ vs. $9 \%)$. This difference was statistically significant $(p=0.05)$.

Those women who had a history of STD were more likely to be HBs Ag positive but this difference was not found to be statistically significant $(10.6 \%$ vs9.2\%) ( $p$ value 0.64). These findings are presented in Table 3.

A total of 453 women had undergone traditional scarification. Of these $79 \%$ (356/453) were from the Rift Valley region. The rest were distributed among the other regions with the exception of the Nyanza/Western region that had only one subject with the condition. The overall prevalence of HBs Ag carriage was 11.9\% with Rift valley region having the highest seroprevalence for HBs Ag of $14 \%$ among the subjects with traditional scarification (Table 4).

Only 46 subjects gave a history of having had a blood transfusion. The Rift Valley, Nyanza and the Coast regions together had majority of these subjects (70\%). The highest Hbs Ag detection rate of 33.3\% was found in Eastern province but the numbers were small. Although blood transfusion had the highest 
Table 2. HBs Ag seroprevalence among the different age groups.

\begin{tabular}{cccc}
\hline Age group in years & $\begin{array}{c}\text { HBs Ag positive } \\
\text { No. (\%) }\end{array}$ & $\begin{array}{c}\text { HBs Ag negative } \\
\text { No. }(\%)\end{array}$ & $\begin{array}{c}\text { Total } \\
\text { No. (\%) }\end{array}$ \\
\hline$[12-22]$ & $70(9)$ & $699(91)$ & $769(100)$ \\
{$[23-27]$} & $72(10)$ & $666(90)$ & $738(100)$ \\
{$[28-43]$} & $63(9)$ & $626(91)$ & $689(100)$ \\
Total & 205 & 1991 & 2196 \\
\hline
\end{tabular}

Table 3. Comparison between HBs Ag seroprevalence and all associated factors.

\begin{tabular}{ccccc}
\hline & HBs Ag+ (n (\%)) & OR & $95 \%$ of OR & $p$ value \\
\hline No Scarification & $151(11.9 \%)$ & 1.441 & $1.037-2.004$ & 0.029 \\
BT $^{*}$ & $11(23.9 \%)$ & 3.195 & $1.597-6.391$ & 0.001 \\
No BT & $194(9 \%)$ & & & \\
Alcohol & $12(15.6 \%)$ & 1.858 & $0.986-3.5$ & 0.052 \\
No Alcohol & $193(9 \%)$ & & & 0.640 \\
STD & $10(10.6 \%)$ & 1.174 & $0.6-2.299$ & \\
No STD & $195(9.2 \%)$ & & & \\
Total & $205(9.3 \%)$ & & & \\
\hline
\end{tabular}

*BT-Blood transfusion, STD—Sexually transmitted disease.

Table 4. Regional comparison of HBs Ag seroprevalence and scarification.

\begin{tabular}{cccc}
\hline Study region & HBs Ag $(\mathrm{n} / \mathrm{N}) \%$ & $95 \%$ CI \\
\hline Nairobi & $0 / 24$ & 0 & {$[0.0 ; 14.2]$} \\
Coast & $1 / 35$ & 2.9 & {$[0.1 ; 14.9]$} \\
Nyanza/Western & $0 / 1$ & 0 & {$[0.0 ; 97.5]$} \\
Rift Valley & $50 / 356$ & 14 & {$[10.6 ; 18.1]$} \\
Eastern & $1 / 12$ & 8.3 & {$[0.2 ; 38.5]$} \\
Central & $2 / 25$ & 8.0 & {$[1.0 ; 26.0]$} \\
Total & $54 / 453$ & 11.9 & {$[9.1 ; 15.3]$} \\
\hline
\end{tabular}

$\mathrm{N}=$ Number of subjects with scarification; $\mathrm{n}=$ Number positive for HBs Ag.

percentage HBs Ag seroprevalence overall of 23.9\% (Table 5) the numbers were small but evenly distributed among all the regions.

The number of subjects who gave a history of alcohol intake was 77 and of these 45 (58.4\%) were from Nairobi followed by the Rift Valley region that had $20(26 \%)$ of the subjects. The Rift Valley region had the highest seroprevalence of $\mathrm{HBs} \mathrm{Ag}$ of $35 \%$ followed by the Eastern region that had only 1 subject positive for HBs Ag out of only 3 who reported intake of alcohol giving a relatively high prevalence of $33.3 \%$ due to the small number of subjects. Nairobi despite its relatively larger number of subjects who consumed alcohol had only $8.9 \% \mathrm{HBs} \mathrm{Ag}$ seroprevalence (Table 6). 
Table 5. Regional comparison of HBs Ag and blood transfusion.

\begin{tabular}{cccc}
\hline Study region & \multicolumn{2}{l}{ HBsAg $(\mathrm{n} / \mathrm{N}) \%$} & $95 \% \mathrm{CI}$ \\
\hline Nairobi & $1 / 4$ & 25 & {$[0.6 ; 80.6]$} \\
Coast & $2 / 9$ & 22.2 & {$[2.8 ; 60.0]$} \\
Nyanza/Western & $2 / 11$ & 18.2 & {$[2.3 ; 51.8]$} \\
Rift Valley & $3 / 12$ & 25.0 & {$[5.5 ; 57.2]$} \\
Eastern & $2 / 6$ & 33.3 & {$[4.3 ; 77.7]$} \\
Central & $1 / 4$ & 25.0 & {$[0.6 ; 80.6]$} \\
Total & $11 / 46$ & 23.9 & {$[12.6 ; 38.8]$}
\end{tabular}

$\mathrm{N}=$ Number of subjects with Blood transfusion; $\mathrm{n}=$ Number positive for HBs Ag.

Table 6. Regional comparison of HBs Ag and STD.

\begin{tabular}{cccc}
\hline Study region & \multicolumn{2}{l}{$\operatorname{HBs} \mathrm{Ag}(\mathrm{n} / \mathrm{N}) \%$} & $95 \% \mathrm{CI}$ \\
\hline Nairobi & $0 / 14$ & 0 & {$[0.0 ; 23.2]$} \\
Coast & $0 / 0$ & 0 & {$[0.0 ; 30.8]$} \\
Nyanza/Western & $1 / 12$ & 8.3 & {$[0.2 ; 38.5]$} \\
Rift Valley & $7 / 28$ & 25 & {$[10.7 ; 44.9]$} \\
Eastern & $2 / 9$ & 22.2 & {$[2.8 ; 60.0]$} \\
Central & $0 / 21$ & 0 & {$[0.0 ; 16.1]$} \\
Total & $10 / 94$ & 10.6 & {$[5.2 ; 18.7]$}
\end{tabular}

$\mathrm{N}=$ Number of subjects with STD; $\mathrm{n}=$ Number positive for HBs Ag.

The women who gave a history of having had STD were 94. The highest number of these women which was in the Rift Valley region where the highest seroprevalence of $\mathrm{HBs} \mathrm{Ag}$ of $25 \%$ was also demonstrated. This was followed by the Central [21] and then Nairobi [14] regions where no HBs Ag positive cases were found and lastly Eastern region where there were 9 cases of STD and two were positive for $\mathrm{HBs}$ Ag giving a relatively high percentage of $22.2 \%$ (Table 7).

\section{Discussion}

The seroprevalence of HBs Ag among pregnant women in this study was 9.3\% (205 out of 2196) suggesting high endemicity in Kenya. This finding is in keeping with those from other (mainly developing) countries where similarly high rates have been reported in pregnant women, Nigeria (11.6\%), Papua New Guinea (11\%), Hong Kong of China (10\%), Taiwan of China (12\%) and an extremely high rate in Cameroon (25.3\%) while intermediate rates of $6.5 \%$ have been described in Congo and Zambia [9]. Much lower rates of $1.35 \%, 3.7 \%$ and $0.88 \%$, have been reported in Ethiopia, Mexico and Israel respectively [9] [10] [11].

In a series of studies, there has been significant regional differences in the seroprevalence of $\mathrm{HBs} \mathrm{Ag}$ [6] [12] [13] [14] [15] where higher prevalence rates 
Table 7. Regional comparison of HBs Ag and alcohol intake.

\begin{tabular}{cccc}
\hline Study region & \multicolumn{2}{l}{$\operatorname{HBsAg}(\mathrm{n} / \mathrm{N}) \%$} & $95 \% \mathrm{CI}$ \\
\hline Nairobi & $4 / 45$ & 8.9 & {$[2.5 ; 21.2]$} \\
Coast & $0 / 5$ & 0 & {$[0.0 ; 52.2]$} \\
Nyanza/Western & $0 / 1$ & 0 & {$[0.0 ; 97.5]$} \\
Rift Valley & $7 / 20$ & 35 & {$[15.4 ; 59.2]$} \\
Eastern & $1 / 13$ & 33.3 & {$[0.8 ; 90.6]$} \\
Central & $0 / 3$ & 0 & {$[0.0 ; 70.8]$} \\
Total & $12 / 77$ & 15.6 & {$[8.3 ; 25.6]$} \\
\hline
\end{tabular}

$\mathrm{N}=$ Number of subjects who reported alcohol intake; $\mathrm{n}=$ Number positive for $\mathrm{HBs} \mathrm{Ag}$.

have been demonstrated in rural areas compared to urban areas. In this study the prevalence of HBs Ag was higher in all three rural sites in the Rift Valley region compared to the city of Nairobi. This observation is consistent with the fact that urbanization has been found to be associated with lowered transmission of HBV [14]. However, research in Ethiopia found confounding data demonstrating higher prevalence in urban area due to overcrowding [9]. HBV transmission may be enhanced in rural areas due to lower SES along with poor personal hygiene habits which encourage transmission in manners such as sharing of personal paraphernalia like; razor blades and tooth brushes while other modes of transmission in rural areas may be through contaminated skin injuries and insect bites [15] [16]. Regional differences may therefore depend on the different cultural practices and environmental risk factors as has been described before in Kenya [13], other African countries [16], Israel, Brazil, and Iran [11] [17] [18] respectively. Another study in Kenya more than a decade ago also identified a greater risk for HBV infection in women with increased parity implicating child birth as a another possible risk factor [19]. In Ghana other risk factors were shown to include sharing of towels, chewing gum and candies, biting of finger nails and scratching backs of carriers [20]. The latter would favor transmission between mothers and their children during bathing.

When age was considered in the following groups; $12-22,23-27$ and $28-43$, the prevalence rates were similar at $9 \%, 10 \%$ and $9 \%$ respectively. The rise in prevalence during the second decade of life was not observed here [12] [13]. In Mexico researchers found the seroprevalence of HBs Ag to increase with age in pregnant women [10] and in Iran it was found that the carrier prevalence rates increased with age with the highest prevalence found in the age group 50-59 years [18]. However, a study in Ethiopia found no association between age and HBs Ag seroprevalence in pregnant women though the sample size was small [9]. In areas where HBV is endemic the force of infection is typically highest in the youngest age groups and declines throughout childhood often rising slightly in adults, the latter presumably due to sexual transmission [1]. It is possible therefore to predict that most of these women could have acquired the infection 
in early childhood.

History of STD was not found to be a significant associated factor for transmission of HBV infection in this study. However, STD has been implicated and found to be a significant risk factor for HBV infection transmission in many previous studies [3] [9] [10] [17] [18]. The information obtained for two of the potential risk factors namely history of STD and alcohol consumption may have been inaccurate because these two behaviours are considered a taboo in many ethnic groups especially in the rural areas and therefore the women may not have give the correct information and may have withheld information suggesting that there could have been more women with this risky behaviour.

Ironically, more subjects in the rural Rift Valley region gave a history of having had an STD followed by Central region then Nairobi which by virtue of being a city would have been expected to have the highest prevalence of STD [17]. This may be a true occurrence or the women may not have been sure of the diagnosis. Surprisingly none of the 14 subjects who reported a history of STD in Nairobi were positive for HBs Ag.

Alcohol as an associated factor was investigated because this habit is associated with risky sexual behavior and also because chronic alcohol intake has adverse effects on the liver. The study found a significant association of alcohol intake with HBV infection. The history of alcohol use was reported more frequently in Nairobi where the subjects were likely to be more open about their habits compared to those from rural areas. Nevertheless, the highest rate of HBV infection was found in those who consumed alcohol in the Rift Valley region. A possible explanation is the frequent consumption of strong, local brews in this region possibly being associated with lowered immunity and therefore a higher infection rate.

Traditional scarification was found to be a significantly associated factor for HBV transmission in agreement with other studies [9] [10] [15] [18]. Scarification was confirmed by physical examination and thus constituted the most reliable data from the study. It is practiced by specific ethnic groups as a mark of beauty, most commonly in the Rift Valley region, followed by the Coast and then the Central region. The likely mode of horizontal transmission of HBV is through tattooing and traditional scarification due to the re-use of contaminated instruments used in these ceremonies [16].

Blood transfusion has been documented widely as a risk factor for HBV transmission [3] [9] [10] [17] [21]. However, studies in Nigeria, Eastern Kenya and Ghana did not implicate blood transfusion as a significant risk factor for infection [4] [19] [20]. The women in this study who had undergone blood transfusion were mainly from regions where malaria is endemic in Kenya, namely Nyanza, Coast and Rift Valley. Among these women, those who had been transfused were significantly more likely to be HBV positive than those who had never been transfused (23.9\% versus $8.9 \%$ ). Seroprevalence of $\mathrm{HBs} \mathrm{Ag}$ in blood donors in Kenya has been estimated to range between $4.5 \%$ and 7\% [22] [23] in 
comparison to documented high rates of $8 \%-14 \%$ in Ethiopia and only $0.11 \%$ in Mexico [9] [10]. National Screening for HBs Ag in blood for transfusion in Kenyan using KEMRI Hep II Kit was approved by the National AIDS \& STD Control and initiated in June 2000 [24]. Despite this intervention Blood transfusion was found to be the risk factor associated with the highest rate of HBs Ag carrier rate of $23.9 \%$ indicating a high possibility of transfusion related acquisition of HBV infection. It is possible that some of the blood meant for transfusion which tests negative for HBs Ag originates from donors who are in the window period of hepatitis B infection. Additionally, the method for screening may not to be sensitive enough and using $\mathrm{HBs} \mathrm{Ag}$ as the only screening tool may be inadequate [23]. Finally, it is probable that some blood is not screened prior to transfusion.

\section{Conclusions}

In conclusion, the prevalence of HBs Ag among the pregnant women in this study was relatively high, with significant risk factors for infection being scarification, history of blood transfusion and alcohol consumption. It is postulated that lowered immunity in pregnancy, coupled with malnutrition and possible parasitic infections, could have predisposed these women to HBV positivity even if the infection was acquired in childhood and had not seroconverted [5] [21] [23].

The study limitations included: Medical history recalls bias, sensitive medical history like STD, use of intravenous drugs and alcohol consumption. Although this paper uses old data that was collected in 2001 and 2002, more recent data in Kenya and its neighbors show a similar trend in the HBs Ag seroprevalence [25] [26] [27].

With the findings from this study, we recommend the following: development of an official policy for HBV prevention in Kenya in addition to increasing antenatal screening for HBs Ag for all women with history of blood transfusion and those with high risk behavior of alcohol intake as well as women who give history of having suffered from STDs. Similarly, early (within 12 hours) vaccination of newborns to mothers who is $\mathrm{HBs} \mathrm{Ag}$ positive and vaccination of all women including pregnant ones who are HBs Ag negative.

\section{Acknowledgements}

Kenya Pediatrics Association would like to thank the following:

1) Aventis Pasteur SA for facilitating and funding the research;

2) Triclinium Clinical Trial Management Marie-Annick and Joyce Katuu Ministry Of Health-Kenyatta National Hospital, Nyeri Provincial General Hospital, Coast Provincial General Hospital and Aga Khan Hospital Mombasa, Nyanza Provincial General Hospital Kisumu, Moi Teaching Hospital Eldoret, Rift Valley Provincial General Hospital Nakuru, AMREF Lopiding Health Facility Lodwar and Isiolo District Hospital; 
3) Kenya Medical Research Institute;

4) All the patients involved in the study;

5) Mr. Lawrence Muthami for Statistical analysis.

\section{References}

[1] Edmunds, W.J., Medley, G.F., Nokes, D.J., O'Callaghan, C.J., Whittle, H.C. and Hall, A.J. (1996) Epidemiological Patterns of Hepatitis B Virus (HBV) in Highly Endemic Areas. Epidemiology \& Infection, 117, 313-325. https://doi.org/10.1017/S0950268800001497

[2] Edmunds, W.J., Medley, F.G. and Nokes, J.D. (1996) The Transmission Dynamics and Control of Hepatitis B Virus in the Gambia. Statistics in Medicine, 15, 2215-2233.

https://doi.org/10.1002/(SICI)1097-0258(19961030)15:20<2215::AID-SIM369>3.0.C O;2-2

[3] Kenneth, W. and Jeffrey, T. (2004) Hepatitis B. American Family Physician, 69, 130-140.

[4] Amigo, U.O. and Chime, A.B. (1990) Hepatitis B Virus Infection in Rural and Urban Populations of Eastern Nigeria: Prevalence of Serological Markers. EAMJ, 67, 539-544.

[5] Bowry, T.R., Pade, J., Omari, M. and Chemtai, A. (1985) A Pilot Study of Hepatitis B Virus Sero Epidemiology Suggests Widespread Immunosuppression in the Nomadic Inhabitants of Turkana District of Kenya. East African Medical Journal, 62, 501-506.

[6] Okoth, F., Mbuthia, J., Gatheru, Z., Murila, F., Kanyingi, F., Mugo, F., Esamain, F., Alavi, Z., Otieno, J., Kiambati, H. and Wanjuki, N. (2006) Seroprevalence of Hepatitis B Markers in Pregnant Women in Kenya. East African Medical Journal, 83, 485-493.

[7] Okoth, F.A., Kaiguri, P.M., Mathenge, E., Tuei, J., Muchiri, S., Owino, N., Kamau, G., Kulundu, J., Njuguna, A. and Tukei, P.M. (1999) KEMRI Hep-Cell II Hepatitis B Surface Antigen Screening Kit. East African Medical Journal, 76, 530-532.

[8] Newcombe, R.G. (1998) Two-Sided Confidence Intervals for the Single Proportion: Comparison of Seven Methods. Statistics in Medicine, 17, 857-872. https://doi.org/10.1002/(SICI)1097-0258(19980430)17:8<857::AID-SIM777>3.0.CO; $\underline{2-\mathrm{E}}$

[9] Mohammed, A. and Solomon, Gs. (2005) Seroprevalence of HBsAg and Its Risk Factors among Pregnant Women in Jimma Southwest Ethiopia. Ethiopian Journal of Health Development, 19, 45-49.

[10] Jose, L.V., Maria, O.C.J., Luis, F.M.E., Michael, A.I. and Hector, G.D. (2003) Seroprevalence of Hepatitis B in Pregnant Women in Mexico. Salud Pública de México, 45, 165-170. https://doi.org/10.1590/S0036-36342003000300005

[11] Bogomolski-Yaholom, V., Granot, E., Linder, N., Adler, R., Korman, S., Manny, N., Tur-Kaspa, R. and Shouval, D. (1991) Prevalence of HBsAg Carriers in Native and Immigrant Pregnant Female Populations in Israel and Passive/Active Vaccination against HBV of Newborns at Risk. Journal of Medical Virology, 34, 217-222. https://doi.org/10.1002/jmv.1890340404

[12] Okoth, F.A., Yamanaka, T., Takayanagi, N., Kaiguri, P.M., Kapttich, D., Tukei, P.M. and Kinuthia, D. (1990) A Community Based Longitudinal Study of Viral Hepatitis B in a Rural Community. East African Medical Journal, 67, 640-649.

[13] Bowry, T.R. (1984) The Pattern of Transmission of Hepatitis B Virus in an Urban 
Population of Kenya. East African Medical Journal, 61, 385-391.

[14] Kew, M.C., Kassiandes, C., Berger, E.L., Song, E. and Dusheiko, G.M. (1987) Prevalence of Chronic Hepatitis B Virus Infection in Pregnant Black Women Living in Soweto. Journal of Medical Virology, 22, 263-268. https://doi.org/10.1002/jmv.1890220310

[15] Vas, G.H., Rose, E.F. and Marimuthu, F (1980) Hepatitis B Antigen and Antibodies in Rural and Urban South Africa Blacks. South African Medical Journal, 57, 868-870.

[16] Kiire, C.F. (1996) The Epidemiology and Prophylaxis of Hepatitis B in Sub-Saharan Africa: A View from Tropical and Subtropical Africa. Gut, 38, S5-S12. https://doi.org/10.1136/gut.38.Suppl_2.S5

[17] Motta-Castro, A.R., Yoshida, E.F., Lemos, E.R., Oliveira, J.M., Cunha, R.V., Lewis-Ximenez, L.L., Cabello, P.H., Lima, K.M. and Martins, R.M. (2003) Seroprevalence of Hepatitis B Virus Infection among an Afro-Descendant Community in Brazil. Memórias do Instituto Oswaldo Cruz, 98, 13-17. https://doi.org/10.1590/S0074-02762003000100002

[18] Mohammad, R.Z., Kazem, M., Ashkan, F., Mohammad, R.M., Ali, Z. and Azita, N. (1996) Epidemiology of Hepatitis B in Islamic Republic of Iran. The Eastern Mediterranean Health Journal, 2, 290-298.

[19] Hyams, K.C., Okoth, F.A., Tukei, P.M., Mugambi, M., Johnson, B., Morrill, J.C., Gray, G.C. and Woody, J.N. (1989) Epidemiology of Hepatitis B in Eastern Kenya. Journal of Medical Virology, 28, 106-109. https://doi.org/10.1002/jmv.1890280210

[20] Martinson, F.E., Weigle, K.A., Royce, R.A., Weber, D.J., Suchindran, C.M. and Lemon, S.M. (1998) Risk Factors for Transmission of Hepatitis B Virus in a Rural District in Ghana. American Journal of Epidemiology, 147, 478-487. https://doi.org/10.1093/oxfordjournals.aje.a009474

[21] Hassan, A. (2000) Prevalence of Hepatitis B Surface Antigen and Risk Factors of HBV Infection in a Sample of Healthy Mothers and their Infants in Sana'a, Yemen. Annals of Saudi Medicine, 20, 464-466. https://doi.org/10.5144/0256-4947.2000.464

[22] Jean-Pierre, A., Shirley, O.O. and Imelda, B. (2004) Blood Transfusion in Sub-Saharan Africa. TATM, 6, 16-23.

[23] Bowry, T.R., Ahmed, Z. and Chemtai, A.K. (1981) Hepatitis B Core Antibody in Volunteer Blood Donors in Kenya. East African Medical Journal, 58, 570-575.

[24] (2002) Implementation of the New Blood Safety Policy. Proceedings of a Consultative Technical Meeting, Nairobi Kenya, 29-30 April 2002, 45.

http://files.unaids.org/en/dataanalysis/knowyourresponse/countryprogressreports/2 012countries/ce_KE_Narrative_Report.pdf

[25] Nyamusi, M.M., Marete, O.T. and Waweru, W.R. (2016) Seroprevalence of Hepatitis B among Pregnant Women in Kigali, Rwanda. International Journal of Community Medicine and Public Health, 3, 3096-3101. https://doi.org/10.18203/2394-6040.ijcmph20163918

[26] Abuelgasim, M.H., Basheer, M.K., Baraka, K. and Abuelgasim, M.H. (2015) Prevalence of Hepatitis B Infection among Pregnant Women at Khartoum Teaching Hospital, Sudan. Journal of US-China Medical Science, 12, 58-63.

[27] Muriuki, B.M., Gicheru, M.M., Wachira, D., Nyamache, A.K. and Khamadi, S.A. (2013) Prevalence of Hepatitis B and C Viral Co-Infections among HIV-1 Infected Individuals in Nairobi, Kenya. BMC Research Notes, 6, 363.

https://doi.org/10.1186/1756-0500-6-363 